\title{
O papel do gênero social nos estudos sociolinguísticos: desafios metodológicos na análise do futuro variável
}

DOI: http://dx.doi.org/10.21165/el.v49i1.2481

\section{Camila Bordonal Clempi ${ }^{1}$ Angélica Rodrigues ${ }^{2}$}

\section{Resumo}

Tendo em vista o tratamento subalterno de investigação da variável gênero enquanto uma categoria fluída de construção e identificação social, histórica e cultural nos estudos sociolinguísticos, objetivamos, neste artigo, discutir os principais desafios metodológicos e apresentar as possibilidades de análise do papel feminino na mudança linguística, mais especificamente na mudança das formas verbais para expressão de tempo futuro no português brasileiro escrito, à luz dos preceitos teóricos e metodológicos da Sociolinguística e da Teoria da Variação e Mudança (WEINREICH; LABOV; HERZOG, 2006 [1968]; LABOV, 2016 [1972]).

Palavras-chave: sociolinguística; gênero social; futuro verbal.

\footnotetext{
1 Universidade Estadual Paulista "Júlio de Mesquita Filho" (UNESP), Araraquara, São Paulo, Brasil; camilabordonal@yahoo.com.br; https://orcid.org/0000-0003-1549-400X

2 Universidade Estadual Paulista "Júlio de Mesquita Filho" (UNESP), Araraquara, São Paulo, Brasil; angelica.rodrigues@unesp.br; https://orcid.org/0000-0003-1470-4634.
} 


\title{
The role of social gender in sociolinguistic studies: methodological challenges in the analysis of the variable future
}

\begin{abstract}
In view of the subaltern treatment of investigation of the gender variable as a fluid category of construction and of social, historical and cultural identification in sociolinguistic studies, we aim, in this article, to discuss the main methodological challenges and present the possibilities of analyzing the female role in linguistic change, more specifically in the change of verbal forms to express the future tense in Brazilian Portuguese writing in the light of the theoretical and methodological principles of Sociolinguistics and Theory of Variation and Change (WEINREICH, LABOV; HERZOG, 2006 [1968], LABOV, 2016 [1972]).
\end{abstract}

Keywords: sociolinguistics; gender; verbal future.

\section{Considerações iniciais}

À luz dos preceitos teórico-metodológicos da Sociolinguística e da Teoria da Variação e Mudança (WEINREICH; LABOV; HERZOG, 2006 [1968]; LABOV, 2016 [1972]), o objetivo de nosso artigo é apresentar e discutir os principais desafios metodológicos relativos à análise do papel do gênero social (feminino) na implementação do futuro perifrástico (1-2) em variação com o futuro sintético (2-3) no português brasileiro escrito. 0 gênero social é tratado, neste trabalho, como uma categoria social que representa o modo fluído pelo qual o sujeito se constrói social, histórica e culturalmente.

(1) Esteve brilhante o sarau promovido pelo G. D. Royal. Entre outras coisas, notou-se: [...], a tolice do Jorge J. e do Halim A. em aspirar ether dos lança-perfumes; vocês qualquer dia vão parar no Juquery (A Cigarra, março de 1923).

(2) Em lugar de deixar a imaginação convencê-la de novos fracassos, controle-a a seu favor, pensando que se deixou impressionar errôneamente, mas que daqui pra frente vai vencer os obstáculos como já venceu antes (A Cigarra, março de 1970).

(3) A tua vida é e será o que sempre foi até hoje: uma saudade à sombra das recordações do passado que não volta mais... (A Cigarra, fevereiro de 1922).

(4) E certamente estará apta a fazer feliz o homem que ama e não a tratá-lo como joguete de seus caprichos (A Cigarra, maio de 1972).

Segundo postula Labov $(1990,2001)$, quando se trata de implementar uma variante inovadora na língua, numa mudança sem consciência social (change from bellow), são as mulheres as líderes do processo de mudança, de modo que são menos conformistas 
(nonconforming) com as normas que não são abertamente prescritas. No caso do futuro perifrástico, estudos advogam que a forma é ausente de avaliação social explícita (OLIVEIRA, 2011; TESCH, 2011; SANTOS, 2012; FIGUEREIDO, 2015) e que, nesse caso, as mulheres estão à frente do uso inovador de expressão de tempo futuro (GIBBON, 2000; OLIVEIRA, 2006).

Buscando entender o papel do gênero feminino na implantação da forma do futuro perifrástico, o nosso estudo ampara as discussões e interpretações dos resultados a partir da adoção de procedimentos teórico-metodológicos que integram a prática social e a performance de gênero.

Nesse sentido, tendo em vista que, na contemporaneidade, o futuro perifrástico substituiu o uso do futuro sintético, não nos é possível testar o condicionamento dessa variável social em sincronias mais recentes (cf. GIBBON, 2000; OLIVEIRA, 2006; SILVA, 2006; BRAGANÇA, 2008; MALVAR; POPLACK, 2008; TESCH, 2011; ALMEIDA, 2015). Remontando às bases da pesquisa sociolinguística e ao papel das mulheres na implementação de uma variante inovadora, procuramos evidenciar (ou não) a liderança feminina quanto ao uso de futuro perifrástico nas décadas de 1920 (1920-1929) e 1970 (1970-1972) por meio de cartas de leitores da revista A Cigarra (público feminino) contrapostos aos dados extraídos de cartas dos jornais A Gazeta e Correio da Manhã (grupo controle). Complementar ao que definimos para a formação dos corpora, Mira (2001, p. 43) garante que "a relação entre revista feminina e as mulheres tem sido marcada pela confiança e pela intimidade [...]. A revista é a mídia mais feminina que existe. Tanto quanto o jornal é masculino".

Fundada em São Paulo, A Cigarra era considerada um periódico ilustrado, destinado ao público em geral, todavia, na medida em que seus conteúdos provocaram o interesse do gênero feminino tornou-se uma revista feminina, trazendo, entre outros aspectos, um espaço de expressão e interesse para as mulheres, como no espaço dedicado às cartas, por exemplo, sendo um importante mecanismo de prática social ${ }^{3}$.

Em relação ao nosso grupo controle, os jornais A Gazeta (São Paulo) e Correio da Manhã (Rio de Janeiro), ainda que destinados ao público em geral, inclinavam-se à opinião masculina, uma vez que (i) a leitura de jornais era associada à intelectualidade (e suposta visão de superioridade masculina); (ii) havia a divulgação de assuntos "tipicamente de homens", segundo o senso comum, tais como, política e esportes, sobretudo o futebol, além de (iii) existir um protagonismo masculino, de modo geral, nas matérias e imagens publicadas.

3 Ainda que a revista feminina possibilitasse esse espaço, a produção de textos, como cartas de leitoras, representa uma configuração de uma norma brasileira feminina de camadas médias e altas, já que a escrita era domínio de poucas (HELLER, 2001), principalmente nas décadas iniciais do século XX. 
Pretendemos, portanto, demonstrar como a escolha de corpus/corpora favoráveis à investigação sociolinguística de sincronias passadas e também como a delimitação de hipóteses e de objetivos admitidos a priori são fundamentais para mobilizar a maneira como alguns fatores sociais (como é o caso do gênero) atuam nos processos de variação/ mudança de fenômenos linguísticos, notadamente na modalidade escrita. O alcance de recursos metodológicos capaz de propiciar tal análise é, pois, um dos desafios deste estudo, que tem a finalidade de colaborar para a descrição sociolinguística e histórica do português brasileiro.

\section{A Sociolinguística Variacionista e o condicionamento do gênero social}

Os processos de variação/mudança são inerentes às línguas naturais e há muito tem sido foco de análise na Linguística, no entanto, é na década de 1960, com os trabalhos fundadores de Weinreich, Labov e Herzog (2006 [1968]) e Labov (2016 [1972), que se instaura de maneira mais efetiva um modelo teórico-metodológico capaz de sistematizar estruturas heterogêneas no sistema linguístico.

Com o advento da Sociolinguística Variacionista houve um rearranjo de princípios linguísticos, até então admitidos, sendo um contraponto, por exemplo, à visão estruturalista saussuriana de que a língua se dissocia do social e de que a mudança apenas pode ser verificada quando concluída. Na perspectiva sociolinguística, a língua é verificada em uso na sociedade e a mudança é passível de mensuração em seu desenvolvimento num plano sincrônico e/ou diacrônico.

Para a compreensão dos motivos que levam determinado fenômeno linguístico a variar e, como uma possível consequência, mudar ao longo do tempo, segundo afırmam Weinreich, Labov e Herzog (2006 [1968]), é de fundamental importância a apreensão da relação entre fatores de natureza interna e externa, uma vez que esses estabelecem uma intrínseca relação e atuam em simultaneidade na língua.

Dentre as variáveis extralinguísticas tradicionalmente controladas em interação com fenômenos variáveis, um papel importante tem sido conferido ao gênero, também entendido em termos de "sexo" ou "sexo/gênero" na literatura sociolinguística. Sustenta essa proposta a hipótese de que a diferenciação das relações determinadas entre homens e mulheres pode explicar, junto a outros aspectos, os processos de variação/mudança.

Para desvelar essa categoria social, Labov (1990, p. 205-206) propõe o Paradoxo do Sexo e elabora dois princípios básicos para o tratamento de um fenômeno variável, amplamente aceitos nos estudos da área como hipóteses clássicas: "(i) em casos de variação estável, homens usam com mais frequência as formas não-padrão do que as mulheres; (ii) na maioria dos casos de mudança linguística, mulheres usam com maior 
frequência formas inovadoras do que os homens"4. Tais princípios são revisados por Labov (2001), admitindo a substituição do termo na definição, Paradoxo do Gênero, e acrescentando a noção de conformismo: (iii) em mudanças com consciência social (changes from above), mulheres usam com maior frequência formas de prestígio do que os homens - são mais conformistas com as normas abertamente prescritas; (iv) em mudanças sem consciência social (changes from below), mulheres usam com maior frequência formas inovadoras do que os homens - são menos conformistas com as normas que não são abertamente prescritas.

Ainda assim, não podemos nos afastar do fato de que, em muitos estudos sociolinguísticos do Brasil, em especial, os de primeira onda cujo objetivo principal é identificar padrões regulares de distribuição das variantes linguísticas usadas por comunidades de fala sociodemograficamente definidas (ECKERT, 2012), as interpretações atribuídas à categoria social gênero como uma variável passível de ser controlada e descrita estatisticamente são aleatórias ou circulares. Como afirma Freitag (2015), as verificações (i) recaem em generalizações de resultados estatísticos pouco confiáveis; e, em consequência, no entendimento de que (ii) se são as mulheres que mais usam determinada variante em comparação aos homens, automaticamente, essa forma é prestigiada e (iii) se é assumido de início que a variante é prestigiada, automaticamente, a conclusão é de que mulheres tendem a usá-la mais do que os homens.

É necessária, portanto, a revisão das interpretações assumidas que referenciam o gênero e a sua relação aos processos de variação/mudança na língua. Uma hipótese bem delimitada desde as etapas preliminares da pesquisa, por exemplo, é fundamental, tal como aponta Freitag (2015), uma vez que é prática corriqueira controlar a variável e somente depois buscar por explicações dos resultados, o que deixa implícito um tratamento subalterno de análise. Do mesmo modo, considerar o tempo e a comunidade em estudo auxilia a investigação e explicações do que subjaz a mudança. Paiva (2013) também pontua que o cruzamento dessa variável com outras de mesma natureza leva à verificação dos padrões emergentes da correlação entre os aspectos internos e externos da língua.

Da mesma maneira, é importante ressaltar que o conceito de gênero, na teoria social, é variável, embora um ponto de convergência seja a rejeição de premissas universalistas na distinção sexo/gênero, como pontua Piscitelli (2002). Para Butler (2003 [1990]), por exemplo, o gênero é visto como uma construção social que, por sua vez, é fundamentada nas relações entre sujeitos em contextos próprios. Segundo advoga, "como um fenômeno

4 No original: "(i) In stable sociolinguistic stratification, men use a higher frequency of nonstandard forms than women.(ii) In the majority of linguistic changes, women use a higher frequency of the incoming forms than men" (LABOV, 1990, p. 205-206). 
inconstante e contextual, o gênero não denota um ser substantivo, mas um ponto relativo de convergência entre conjuntos específicos de relações, cultural e historicamente convergentes" (BUTLER, 2003 [1990], p. 29) e pode ser entendido, desse modo, como uma construção social do sexo, mas que transcende a distinção biológica.

Nos trabalhos sobre o futuro variável poucos são aqueles que analisam o gênero, de modo que a maioria se ampara no caráter biológico, mesmo que as explicações sejam de natureza social. Dentre eles, citamos Gibbon (2000) e Oliveira (2006), que chegam a conclusões semelhantes quanto ao condicionamento do sexo feminino na implementação da variante inovadora de futuro. As autoras apontam que, embora seja identificada uma tendência de que as mulheres assumem uma postura linguística mais conservadora em relação aos homens, especialmente em situações de maior monitoramento da fala, como a mudança de futuro se trata de uma mudança em andamento, as análises corroboram, segundo afırmam, a hipótese de Labov (1990) sobre o "Paradoxo do Sexo", terminologia por elas adotada: mulheres são mais conservadoras em casos de variação estável e mais inovadoras, por outro lado, em casos de mudança, sendo líderes desse processo.

Entretanto, as interpretações dos dados propostas por Gibbon (2000) e Oliveira (2006), no que se refere ao papel social desempenhado por mulheres, parecem estar mais baseadas numa visão estereotipada e de senso comum. As autoras explicam que a inovação linguística está relacionada à nova posição social feminina adquirida na sociedade, sempre referida como "conquistas de espaço", o que dentro de uma teoria social pode ser problematizada, tendo em vista a complexidade envolvida na interpretação do papel das mulheres como força de trabalho ${ }^{5}$. Desse modo, nesses estudos podemos encontrar lacunas referentes ao entendimento do gênero, já que não são apresentadas evidências dessas transformações sociais, tampouco uma análise mais detalhada da comunidade em estudo quanto a essa variável. Faltam nas pesquisas sociolinguísticas, de um modo geral, uma observação mais apurada das questões relacionadas ao Paradoxo do Gênero a partir de uma teoria social, capaz de dar suporte à compreensão do papel do gênero feminino na implementação de variantes inovadoras, como no caso do futuro perifrástico, já que há indícios (ainda que poucos) de que as mulheres estão à frente desse processo. A hipótese norteadora do nosso estudo é, portanto, a de que o uso do futuro perifrástico em textos escritos pode estar associado ao gênero feminino.

5 Sobre isso, Goldman (2014) argumenta que, embora as mulheres ingressassem na força de trabalho, ainda eram responsáveis pela criação dos filhos e demais trabalhos que envolviam o ambiente familiar (como cozinha e limpeza, por exemplo). Desse modo, "as responsabilidades domésticas das mulheres impediam-nas de ingressar nos domínios públicos do trabalho, da política e das empreitadas criativas em pé de igualdade com os homens" (GOLDMAN, 2014, p. 21). 


\section{Procedimentos e desafios metodológicos}

A escolha de corpora favoráveis à nossa investigação, que visa à compreensão do papel do gênero feminino na mudança linguística, pode trazer à luz aspectos sociais de gênero ainda não explorados em outros estudos sociolinguísticos. Desse modo, optamos por analisar a variação/mudança de futuro em duas sincronias pretéritas (década de 1920 e início de 1970) por meio de corpora que representam um público feminino (cartas de leitoras da revista A Cigarra) contrapostas a corpora de públicos não-especificados, denominados de grupo controle (cartas de leitores dos jornais A Gazeta e Correio da Manhã) ${ }^{6}$. É a partir desse procedimento metodológico de comparação, pois, que nos é possível verificar, a partir das diferenças, como se estabelece a implementação do futuro perifrástico e as possíveis interferências de questões de gênero nesse processo.

Escolhemos a revista A Cigarra para a formação dos corpora, já que uma das características definidoras da impressa feminina é o público a que se destina, fato muito sensível em nosso estudo. Com uma linguagem mais afetiva e mais pessoal, veicula conteúdo capaz de influenciar toda a vida em sociedade. Buitoni (1981, p. 125) salienta que:

[...] o texto na imprensa feminina sempre vai procurar dirigir à leitora, como se estivesse conversando com ela, servindo-se de uma intimidade de amiga. Esse jeito coloquial, que elimina a distância, que faz as ideias parecerem simples, cotidianas, frutos do bom senso, ajuda a passar conceitos, cristalizar opiniões, tudo de um modo tão natural que praticamente não há defesa. A razão não se arma para uma conversa de amiga.

Essa segmentação surge, no Brasil, principalmente como um modo de veicular (ou impor) certa imagem e valores dominantes de gênero de um tempo, que ora atualiza ora conserva os padrões de representação da figura feminina. Nesse sentido, a nossa análise parte da construção de gênero presente na imprensa feminina. Exemplificamos com trechos de cartas de leitoras, transcritos como constam na revista A Cigarra:

(5) [...] Preferiria muito mais vel-a enaltecendo a mulher nas suas virtudes, como espozas, mães, noivas, etc. Não podemos chamar de fracos prestimos a grandiosa cooperação da mulher na guerra. Ella mostrou-se sublime de heroismo e dedicação. E, se ainda era discutido até então o seu valor moral, de agora em diante a magestade dos seus actos colocou-a num throno, tornando-a rainha do mundo. Ao lado do Bem sempre reinará o Mal (isto data do principio do mundo). Porque foi destruida Sodoma? Nem por isso deixarão de existir almas eleitas, amigas do Bello e do Bom que atravessarão incolumes entre os vicios da Sociedade. E serão justamente as almas ingenuas confiantes no futuro e não as eivadas de septicismo e desalentadas pela descrença. (A Cigarra, abril de 1921).

6 As amostras encontram-se em bancos de dados digitais (Arquivo Público de São Paulo e Biblioteca Nacional Digital), disponíveis para acesso online (cf. Referências). 
(6) até que ponto um cara pode avançar? Fico desnorteada, ninguém nunca esclarece de fato êste assunto. Perco oportunidade de namorar um cara mais maduro com mêdo de não ser bacana com êle, sem saber como reagir. Já namorei rapazes ótimos (não que fôssem santos, é claro) e que foram muito diferentes. O problema não é só seu, mas de tôda adolescente em geral. O tabu do sexo provoca as maiores angústias quando o sexo é uma função natural e não há nada de errado com ele [...]. Mil fatores vão determinar o comportamento sexual de cada pessoa: educação, religião, meio ambiente e uma infinidade de circunstâncias imprevisíveis. Eu poderia dar a minha opinião a respeito [...], mas se essa opinião não coincidir com seus princípios e não estiver de acôrdo com a voz da sua consciência, você continuará igualmente perturbada e angustiada. [...], haverá sempre um exemplo bem ou mal sucedido. [...]. Você só precisa saber agir em relação a você mesma e não em relação a $A$ ou B. Do contrário, você será um eterno fantoche na mão dos namorados [...]. Faça a experiência e verá como todos os problemas desaparecem como um passe de mágica. Seja você mesma sem qualquer circunstância e não terá receio de enfrentar nenhum tipo de homem: nem o puritano nem o devasso, porque você estará segura de você mesma e terá um rumo claro e reto diante de si para seguir. Seja fiel a você mesma, ao que a sua consciência Ihe indicar como certo, e não mais perguntará a alguém como deve agir. [...]. (A Cigarra, julho de 1971)7.

Observamos, por meio dos fragmentos (5-6), que os textos veiculados nesse meio de comunicação carregam traços que deixam transparecer uma identificação social, cultural e histórica de gênero feminino, relacionada ao público-alvo. Em (6), por exemplo, o tema tratado é sexo e relacionamento afetivo. A revista, com um tom sutil, aconselha a leitora a seguir um determinado comportamento, prática recorrente nessa segmentação editorial, já que (in)diretamente o objetivo da imprensa destinada às mulheres é construir uma representação de gênero. Por essa razão, há interesse em controlar um contexto de publicação feminina em nosso estudo.

Vale acrescentar que o modelo de carta adotado na década de 1970 permitia uma identificação entre revista e leitoras, uma vez que a edição se servia de um tom amigável para moldar identidades de gênero feminino. Conforme aponta Scalzo (2016, p. 76), "conhecendo o leitor, sabe-se exatamente o tom com que se dirigir a ele. É preciso escrever na língua dele ou, como diria o jornalista Eugênio Bucci, em 'leitores' (sic)", oferecendo-lhe um tratamento de igual para igual em um verdadeiro bate-papo entre amigas.

Como um contraponto de investigação, vimos a necessidade de comparar os resultados obtidos por meio d'A Cigarra com outros corpora, que representassem um público diferente do feminino, uma vez que somente o contexto de publicação feminina não nos traria respostas suficientes para o objetivo de pesquisa. Por essa razão, assumimos a priori que os dados deveriam ser interpretados também segundo um "grupo controle" em que seria possível mobilizar, a partir das diferenças de usos linguísticos, qual é o papel feminino na mudança de futuro.

70 texto em itálico refere-se à carta-resposta da revista. 
Nosso grupo controle (A Gazeta e Correio da Manhã), em teoria, é composto por jornais destinados para o público em geral. Portanto, enquanto a imprensa feminina é fortemente marcada pelo gênero do público-alvo, os jornais parecem se servir de uma aparente "neutralidade" quanto a uma representação de gênero. Vejamos exemplos de cartas de leitores dos corpora selecionados para a pesquisa:

(7) Sr. redactor - Sou productor de assucar e, por isso, interessado directamente nesse producto. Lendo, ha dias, que a Bolsa de Mercadorias ia estudar a classificação do assucar para o corrente anno, vim a S. Paulo na esperança de ser ouvido pelos senhores que dirigem aquella associação. [...] Pois é lá possivel que este anno possa vigorar a mesma classificação do anno passado? Pois esses senhores ignorarão que as chuvas que temos tido em excesso este anno não vão influir poderosamente na qualidade dos productor? [...] Ou eu estou doido, ou então os senhores da Bolsa de Mercadorias que vão tratar de outro officio, e não queiram nunca parecer aos olhos dos ignorantes como pessoas entendidas em cousas que não lhes competem. (A Gazeta, janeiro de 1920).

(8) Nesse caso da Loteria Esportiva, eu também gostaria de dar a minha sugestão. Primeiro: não concordo, em absoluto, com as reclamações do Comércio quanto aos prejuízos causados pela Loteria. Ninguém vai se privar de comprar o que precisa por jogar uns Cr\$2,00 num cartão, nem o Comércio vai enriquecer com êsses mesmos Cr\$2,00, porquanto quando o jôgo do bicho era livre as apostas nunca prejudicaram o Comércio, pelo menos nunca me lembro de ter ouvido tal coisa e se jogava na mesma proporção. E o que se vai comprar com Cr\$ 2,00 sr. Redator? Não será o Comércio que está prejudicando o povo? Segundo: não acho que se deva limitar o número de apostas, há muito benefício proporcionado pela Loteria e diminuindo a arrecadação forçosamente diminuirá o benefício, perdendo a Loteria a razão de sua existência. [...]. Terceiro: a minha sugestão para que haja mais ganhadores é a mais viável, diminuir o número de jogos de 13 para 10 e então ficarão satisfeitos. [...]. Portanto, sr. redator, nada de limitação de apostas e sim 10 jogos e não haverá necessidade de segundos e terceiros lugares como muitos sugerem [...]. (Correio da Manhã, janeiro de 1971).

Diferentemente das cartas da revista $A$ Cigarra, as cartas dos jornais serviam como um porta-voz para que os leitores informassem, reclamassem e opinassem sobre acontecimentos da sociedade, como é possível observar nos trechos (7-8) acima, em que em (7) se discute sobre a bolsa de mercadorias e em (8), sobre o caso da loteria esportiva.

Quanto à escrita das cartas de leitores nos diferentes veículos de comunicação que perfazem nossos corpora, não há informações sobre possíveis interferências de revisão editorial, ou seja, não há garantias de que as cartas passaram ou não por alguma correção em termos gramaticais. Os resultados de nosso estudo, portanto, também devem ser lidos levando em consideração esse fato. 
Não livre de questionamentos, alguns desafios e aparentes problemas se inserem nessa metodologia. Perpassa a pesquisa o seguinte questionamento: como a análise numa perspectiva de gênero é possível à medida em que é realizada a partir de textos escritos, cuja autoria não pode ser comprovada? Em vista de problemas como (i) ausência de informações sobre os perfis sociais dos remetentes; (ii) inviabilidade de controle desta variável por informante; e (iii) diferentes graus de formalidade das cartas de acordo com o meio de comunicação.

Ao lidarmos com cartas de leitoras publicadas em revista feminina, sustentamos que essa imprensa parte de uma construção de gênero feminino hegemônica ao criar um modelo ideal de mulher de sua época. Nas palavras de Prado (2011, p. 16):

[...] a mídia possui influência fundamental na construção da identidade feminina, haja vista que faz parte do contexto social e cultural da modernidade. Por apresentar seus modelos de representação provoca no receptor um processo de "identificação/projeção" - nos termos de Morin (1997); com isso, as mulheres, em contato com os produtos culturais da mídia, se identificam com o que representam e projetam sua identidade em torno disso.

A mídia feminina, nesse sentido, tem como principal característica oferecer estilos de vida e de representações de gênero e é capaz de interferir nas construções de identidades e nas relações sociais, conforme afirma Prado (2011, p. 12). Compreendendo que os textos d'A Cigarra são direcionados de modo muito particular para as mulheres, neste trabalho, importa-nos, portanto, a análise do grupo de leitoras que integram esse quadro de identificações do que propriamente o controle de cada escrevente-leitora. Buscamos, dessa maneira, discutir os efeitos do gênero feminino na implementação do futuro perifrástico a partir da performance de gênero configurado na revista. Isso implica que a nossa investigação se dá por meio de um estereótipo, uma vez que a imprensa feminina constrói e molda as leitoras a partir de um padrão hegemônico e interpreta a mulher de acordo com o que a sociedade determina.

Nesse sentido, consideramos que a análise de textos escritos, como os selecionados aqui, revela mais aspectos sobre o gênero social do que, por exemplo, a análise de bancos de dados sociolinguísticos de fala, pois, na maioria das vezes, a estratificação dos informantes é feita com base no sexo biológico.

O terceiro problema, acima citado, tem relação com o gênero textual que compõe os corpora. Um dos motivos para que optássemos por trabalhar com carta de leitores se deve ao fato de que, segundo Marcuschi (2007), refere-se a um gênero textual misto, com níveis mais ou menos formais, a depender da organização do texto e do espaço em que é veiculado, de modo que pode ser um contexto favorável para a verificação empírica de fenômenos linguísticos variáveis. 
Todavia, alguns trabalhos ancorados em Marcuschi (2007) afirmam que cartas de leitoras de revista feminina podem ser interpretadas como menos formais. Assim, é de se esperar que o futuro perifrástico, uma forma inovadora na língua, seria mais incidente nesse espaço do que nos jornais, marcados por um uso mais formal. A interpretação dos resultados poderia atender a essa perspectiva, porém, temos a hipótese de que os graus de formalidade dos textos em análise dependem, entre outros aspectos, do espaço ideologicamente marcado pelo gênero. Como a proposta da revista, com as cartas de leitoras, é promover um diálogo amigável com o público-alvo que tenciona ao consumo, consideramos que a aproximação (linguística e social) é suporte para a identificação de gênero e pode ter relação com o caráter mais informal da escrita.

Por meio de amostra representativa é que buscamos o caráter social, e não biológico, da categoria de gênero, a fim de entender o papel do gênero feminino no processo de mudança linguística por meio de uma metodologia que pode ser considerada mais eficaz para esse tipo de investigação.

Passemos à frente a análise quantitativa geral dos dados, pela qual é possível verificar como conduzimos a pesquisa.

\section{Análise geral dos dados}

No total, obtivemos 1.105 dados de formas variáveis de futuro (futuro sintético e perifrástico), conforme dispostos na tabela seguinte:

Tabela 1. Distribuição geral das variantes de futuro conforme o período (décadas de 1920 e 1970) e contexto (revista e grupo controle)

\begin{tabular}{c|c|c|c|c|c|c|c|c} 
& \multicolumn{4}{c|}{$\begin{array}{c}\text { Década de 1920 } \\
\text { (1920-1929) }\end{array}$} & \multicolumn{4}{c}{$\begin{array}{c}\text { Década de 1970 } \\
\text { (1970-1972) }\end{array}$} \\
\cline { 2 - 10 } & \multicolumn{2}{c}{ A Cigarra } & Grupo Controle & \multicolumn{2}{c}{ A Cigarra } & Grupo Controle \\
\cline { 2 - 10 } & n. & $\%$ & n. & $\%$ & n. & $\%$ & n. & $\%$ \\
\hline Futuro Sintético & 257 & $89,5 \%$ & 290 & $91,2 \%$ & 233 & $69,8 \%$ & 136 & $81,8 \%$ \\
\hline Futuro Perifrástico & 30 & $10,5 \%$ & 28 & $8,8 \%$ & 101 & $30,2 \%$ & 30 & $18,1 \%$ \\
\hline TOTAL & 287 & $100 \%$ & 318 & $100 \%$ & 334 & $100 \%$ & 166 & $100 \%$ \\
\hline
\end{tabular}

Fonte: Elaboração própria

A seguir, ilustramos trechos de ocorrências de futuro sintético (9-10) e de futuro perifrástico (11-12): 
(9) E, se algum dia, sentires o coração opprimido por alguma cousa inexplicavel a uma lagrima te humidecer os olhos, volta e te estenderei a mão (A Cigarra, fevereiro de 1922).

(10) Acreditamos que, depois dêsses exemplos, o Brasil, por sua vez, dispensará também o uso rotineiro dessa vacinação (Correio da Manhã, dezembro de 1971).

(11) Estamos esperando o apartamento que êle comprou ficar pronto para podermos nos casar, o que ainda vai demorar uns seis meses (A Cigarra, fevereiro de 1970).

(12) E demais, é tão feio chorar. Paulistano não gosta disso. Si esse sr. pensa que vamos repetir a polemica, Santos e Guarany estão enganados. Paulistano não cogita questiunculas [...] (A Gazeta, outubro de 1927).

A partir da Tabela 1, verificamos que, independentemente da sincronia, é o futuro sintético que lidera os usos, em termos de frequência proporcional, nos corpora. Em 1920, a revista A Cigarra apresenta 257 ocorrências da variante conservadora de futuro no total de 287 formas analisadas (89\%). Nesse mesmo período, o grupo controle (jornal A Gazeta) apresenta 290 ocorrências da variante conservadora de futuro no total de 318 formas analisadas (91,2\%). Essa preferência também é observada em 1970, uma vez que verificamos os resultados d'A Cigarra indicam que o futuro sintético foi usado em 233 ocorrências do total de 334 dados (69,8\%). Em relação ao grupo controle (jornal Correio da Manhã), nessa segunda fatia temporal, coletamos 136 ocorrências de futuro sintético no total de 166 dados (81,8\%). Vários são os estudos, a exemplo de Oliveira (2006) e Tesch (2011), que indicam uma relação inversa de preferência das variantes em análise quanto à modalidade da língua: a forma inovadora é a preferida na fala, ao passo que a conservadora é predominante na escrita.

Contudo, quando comparamos os resultados alcançados no contexto de publicação feminina com os de nosso grupo controle, vemos que é a revista que mais produz dados de futuro perifrástico. A revista, em 1920, produz 30 ocorrências da forma inovadora no total de 287 dados (10,5\%), enquanto o grupo controle produz 28 ocorrências no total de 318 dados (8,8\%). Na segunda fatia temporal, a diferença de usos conforme o contexto parece ser mais acentuada, fato que será comprovado estatisticamente mais adiante, já que a revista produz 101 ocorrências de futuro perifrástico no total de 334 dados (30,2\%), ao passo que o grupo controle dispõe de 30 ocorrências no total de 166 dados (18,1\%). Esse resultado é mais bem ilustrado na figura seguinte: 

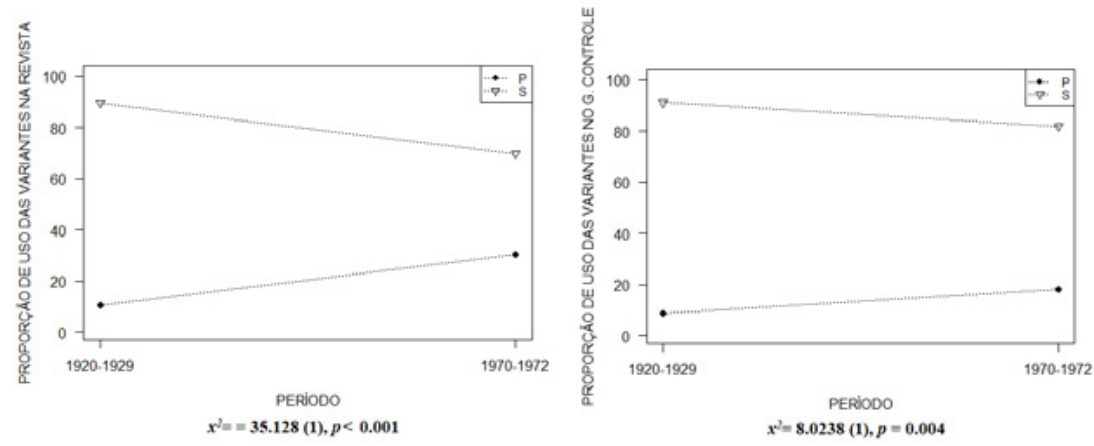

Figura 1. Percurso das variantes de futuro nas sincronias analisadas conforme 0 contexto (revista e grupo controle) ${ }^{8}$

Fonte: Elaboração própria

Tanto nas cartas de leitoras da revista $A$ Cigarra quanto nas do grupo controle (jornais $A$ Gazeta e Correio da Manhã), o período revela, no que se refere à distribuição das variantes de futuro, uma diferença estatisticamente relevante, conforme comprovado pelos testes de significância9 ${ }^{9}$ inseridos abaixo da figura (década de 1920: $p<0,001$; década de 1970: p. = 0,004). Ainda assim, comparando os contextos de publicações, aquele que representa o gênero feminino traz mais evidências da implementação do futuro perifrástico em lugar do futuro sintético, viabilizando, portanto, uma possível discussão da liderança das mulheres nessa mudança linguística.

Ao nos voltarmos para cada sincronia isoladamente, os resultados confirmam que é o contexto feminino o mais favorável ao aparecimento da forma inovadora do que o contexto do grupo controle. Vejamos as figuras 2 e 3 :

$8 \mathrm{Na}$ figura 1, P se refere ao futuro perifrástico e S ao futuro sintético.

9 Nos testes de significância, também conhecidos como testes de qui-quadrado, $x^{2}$ refere-se ao qui-quadrado, seguido por um número equivalente ao seu valor; já entre parênteses encontrase o número referente ao grau de liberdade e após o valor de $p$, ou seja, o valor de significância. Convencionalmente, o resultado é considerado significativo caso $p$ for menor que 0,05. 

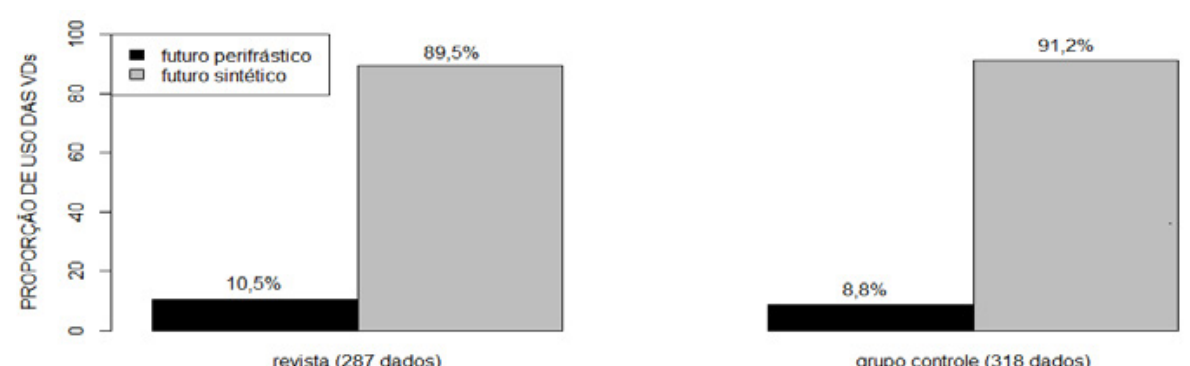

revista (287 dados)

grupo controle ( 318 dados)

CONTEXTO

$x^{2}=0.30163(1), p=0,582$

Figura 2. Distribuição das variantes de futuro na década de 1920 conforme o contexto (revista e grupo controle)

Fonte: Elaboração própria

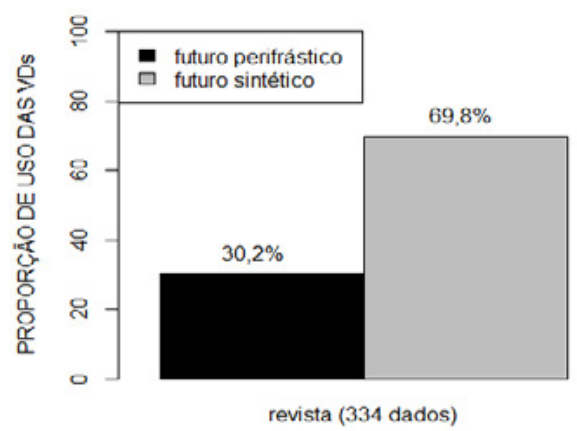

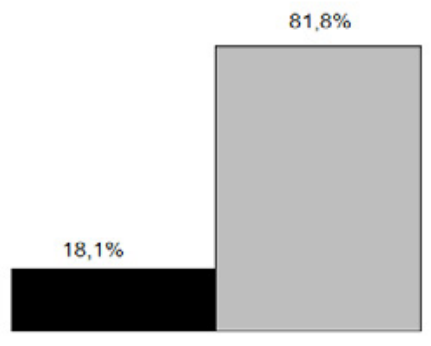

grupo controle (166 dados)

CONTEXTO

$$
x^{2}=7.8724(1), p=0,005
$$

Figura 3. Distribuição das variantes de futuro na década de 1970 conforme o contexto (revista e grupo controle)

\section{Fonte: Elaboração própria}

Por meio da figura 2, verificamos que a variante conservadora de futuro é a mais utilizada e com frequência proporcional bastante semelhante em ambos os corpora, o que consequentemente liga-se ao resultado do teste de significância, que nos indica não haver diferenças significativas na distribuição de nossa variável segundo o contexto (revista versus grupo controle), com o valor de $p=0,582$. O resultado, por outro lado, pode sustentar a premissa de que em 1920 o processo de mudança era incipiente, ao menos nos textos em análise.

Já na sincronia de 1970, observamos uma frequência maior de uso da forma perifrástica de futuro, de modo que a revista demonstra ser um contexto mais produtivo para o andamento desse processo em relação ao grupo controle. O teste de significância 
demonstra que há uma diferença de distribuição da variável conforme o contexto, com o valor de $p=0,005$. Os resultados estatísticos ratificam, portanto, a afirmação de que a publicação feminina é mais propícia ao uso da forma inovadora.

Como explicação para nossos resultados, podemos retomar a hipótese laboviana do Paradoxo do Gênero (LABOV, 1990, 2001), já que, na maioria dos casos de mudança linguística sem consciência social, as mulheres são mais inovadoras do que os homens. Para além, também sustentamos que, pelo menos, três aspectos podem estar envolvidos e imbricados ao caráter inovador feminino neste estudo: (i) alteração de representação da mulher na revista entre uma sincronia e outra; (ii) expansão do perfil socioeconômico e os novos significados das cartas para o público-alvo; e (ii) configuração do texto da revista, como proposta de interação, por exemplo, oferecendo possibilidades de novos arranjos linguísticos.

De modo geral, sobre os aspectos acima relacionados ao gênero feminino na mudança linguística, verificamos que a revista se altera conforme a sociedade se altera, levando as mulheres a novos modelos de comportamento a seguir, embora sempre sujeitas à avaliação masculina ${ }^{10}$. Também observamos que o público feminino, especificamente no início do século XX, era pouco instruído, de modo que a educação apenas atingia às camadas mais altas da sociedade brasileira (HELLER, 2001). Embora A Cigarra, nos anos de 1920, publicasse muitas imagens e fotografias, com a finalidade de atingir o maior número de leitoras possível, é perceptível que os textos dessa fatia temporal eram mais formais. Entretanto, em 1970, a revista conquistava uma quantidade maior de leitoras comparativamente à década de 1920, em consequência ao aumento da educação formal feminina (SARTI, 2004), e alcançava, assim, outras camadas socioeconômicas. Além disso, devido ao auge desse segmento, Buitoni (1981, p. 105) afirma que "enquanto a produção editorial de revistas vai-se aperfeiçoando cada vez mais, os jornais mais preocupados com outras editoras que não a feminina, vão ficando para trás em termos dessa imprensa específica". A Cigarra, na segunda sincronia em análise, concedia mais voz às leitoras nas páginas da seção de cartas, reestruturando o diálogo entre revistaleitora(s).

10 A sujeição à avaliação masculina ocorre, de acordo com Rosaldo (1979, p. 33), porque há uma "desigualdade universal nas avaliações culturais do sexo. A mulher pode ser importante, poderosa e influente, mas parece que em relação ao homem de sua idade e de seu status social, a mulher em todo o lugar carece de poder reconhecido e valorizado culturalmente". Embora a autora faça referência ao "sexo", entendemos que a avaliação cultural é diferenciada conforme o gênero que, em consequência ao sexo, resulta na atribuição de mais status e poder social ao símbolo masculino. 


\section{Considerações finais}

A partir da investigação do papel do gênero feminino na mudança linguística, mais especificamente da mudança de formas para expressar o tempo futuro, neste artigo, tentamos mobilizar como é trabalhada a variável gênero nos estudos sociolinguísticos, bem como as possibilidades metodológicas e de análise estatística dos dados aplicadas em nossa pesquisa, que tencionam a uma verificação conduzida pelo caráter social do gênero.

Com o foco nos desafios enfrentados, propusemos a verificação de corpora representativos do gênero e procedimentos de comparação (público feminino versus público nãoespecificado) com vistas ao objetivo central de estudo: trazer evidências para a liderança feminina na implementação do futuro perifrástico.

Em nossa análise dos dados, pudemos, a partir dos corpora, investigar o papel do gênero feminino na mudança de futuro (futuro perifrástico) no português escrito. Verificamos que futuro sintético é o mais empregado, independente da sincronia em análise. Entretanto, quando comparamos os resultados obtidos a partir dos dados da revista com os dados do grupo controle, é possível observar que é a revista que lidera a frequência de usos, em especial, na segunda fatia temporal (1970-1972). Sugerimos, com base nas análises, o início da implementação do futuro perifrástico nos anos de 1920, que caminha para o andamento da mudança nos anos de 1970 em textos escritos, de modo que esse processo linguístico é mais favorável no contexto de publicação feminina (cartas de leitoras d'A Cigarra).

Como resultado, portanto, vimos que, em consonância com Gibbon (2000) e Oliveira (2006), neste trabalho, o gênero feminino lidera o uso da variante inovadora de futuro (futuro perifrástico). Porém, para além da hipótese clássica laboviana, tentamos acomodar outras interpretações, baseadas na representação de gênero esboçada na revista A Cigarra, trazendo, portanto, uma contribuição ao traçar um possível caminho para que seja contemplado um maior investimento de análises de fatores sociais em textos escritos, principalmente em sincronias pretéritas.

\section{Agradecimentos}

As contribuições apresentadas neste artigo são provenientes da dissertação de mestrado da autora Camila Bordonal Clempi, com financiamento FAPESP/CAPES (processo n. 2017/16959-6). 


\section{REFERÊNCIAS}

ARQUIVO PÚBLICO DE SÃO PAULO. Repositório Digital (Revista A Cigarra). Disponível em: http://www.arquivoestado.sp.gov.br/site/acervo/repositorio_digital/jornais_revistas. Acesso em: 12 fev. 2020.

ALMEIDA, F. S. A expressão variável de futuro verbal no discurso político em três cidades baianas: Salvador, Feira de Santana e Vitória da Conquista. 2015. Dissertação (Mestrado em Estudos Linguísticos) - Universidade Estadual de Feira de Santana, Feira de Santana, 2015.

BIBLIOTECA NACIONAL DIGITAL. Hemeroteca Digital (Revista A Cigarra). Disponível em: http://memoria.bn.br/DocReader/docreader.aspx?bib=003085\&pesq=. Acesso em: 12 fev. 2020.

BIBLIOTECA NACIONAL DIGITAL. Hemeroteca Digital (Jornal A Gazeta). Disponível em: http://memoria.bn.br/DocReader/docreader.aspx?bib=763900\&pesq=. Acesso em: 12 fev. 2020.

BIBLIOTECA NACIONAL DIGITAL. Hemeroteca Digital (Jornal Correio da Manhã). Disponível em: http://memoria.bn.br/DocReader/docmulti.aspx?bib=089842\&pesq=. Acesso em: 12 fev. 2020.

BUITONI, D. H. S. Mulher de papel: a representação da mulher na imprensa feminina brasileira. São Paulo: Edições Loyola, 1981.

BUTLER, J. Problemas de gênero. Feminismo e subversão da identidade. Tradução Renato Aguiar. Rio de Janeiro: Civilização Brasileira, 2003 [1990].

BRAGANÇA, M. L. L. A gramaticalização do verbo ir e a variação de formas para expressar o futuro do presente: uma fotografia capixaba. 2008. Dissertação (Mestrado em Estudos Linguísticos) - Universidade Federal do Espírito Santo, Vitória, 2008.

ECKERT, P. Three waves of Variation Study: The emergence of meaning in the study of sociolinguistic variation. Annual Review of Anthropology, v. 41, p. 87-100, 2012.

FIGUEREIDO, J. G. S. A expressão do futuro verbal na escrita escolar de Irará-BA. 2015. Dissertação (Mestrado em Estudos Linguísticos) - Universidade Estadual de Feira de Santana, Feira de Santana, 2015. 
FREITAG, R. M. K. (Re)discutindo sexo/gênero na sociolinguística. In: FREITAG, R. M. K.; SEVERO, C. G. (org.). Mulheres, Linguagem e Poder - Estudos de Gênero na Sociolinguística Brasileira. São Paulo: Blucher, 2015. p. 17-74.

GIBBON, A. O. A expressão do tempo futuro na língua falada de Florianópolis: Gramaticalização e Variação. 2000. Dissertação (Mestrado em Letras/Linguística) - Universidade Federal de Santa Catarina, Florianópolis, 2000.

GOLDMAN, W. Estado, Mulher e Revolução: política familiar e vida social soviéticas, 19171936. São Paulo: Boitempo. Iskra Edições, 2014.

HELLER, B. Vossas filhas sabem ler? INTERCOM (Sociedade Brasileira de Estudos Interdisciplinares da Comunicação, XXIV Congresso Brasileiro da Comunicação), Campo Grande-MS, 2001. Disponível em: http://www.intercom.org.br/papers/nacionais/2001/ papers/NP4HELLER.pdf. Acesso em: 25 jan. 2019.

LABOV, W. Padrões Sociolinguísticos. Tradução Marcos Bagno, Marta Scherre e Caroline Cardoso. 3. reimp. São Paulo: Parábola, 2016 [1972].

$\angle A B O V, W$. The intersection of sex and social class in the course of linguistic change. Language variation and change, v. 2, n. 2, p. 205-254, 1990.

LABOV, W. Principles of Linguistic Change - Social Factors. Oxford: Blackwell, 2001.

MALVAR, E.; POPLACK, S. O presente e o passado do futuro do Português do Brasil. In: VOTRE, S.; RONCARATI, C. (org.). Anthony Julius Naro e a Linguística no Brasil: uma homenagem acadêmica. Rio de Janeiro: 7letras, 2008. p. 187-207.

MARCUSCHI, L. A. Da fala para a escrita: atividades de retextualização. 8. ed. São Paulo: Ed. Cortez, 2007.

MIRA, M. C. O leitor e a banca de revistas: a segmentação da cultura do século XX. São Paulo: Olho D'Água/Fapesp, 2001.

OLIVEIRA, J. M. A variação do futuro verbal em português: teste de percepção/atitude na cidade de Feira de Santana-BA. Tabuleiro de Letras - Revista do Programa de Pós-Graduação em Estudos de Linguagens, n. 3, p. 1-22, 2011. 
OLIVEIRA, J. M. O futuro da língua portuguesa ontem e hoje: variação e mudança. 2006. Tese (Doutorado em Letras Vernáculas) - Universidade Federal do Rio de Janeiro, Rio de Janeiro, 2006.

PAIVA, M. C. A variável gênero/sexo. In: MOLLICA, M. C.; BRAGA, M. L. (org.). Introdução à Sociolinguística: o tratamento da variação. 4. ed. São Paulo: Contexto, 2013. p. 33-42.

PISCITELLI, A. Recriando a (categoria) mulher? In: ALGRANTI, L. (org.). A prática feminista e o conceito de gênero. Textos Didáticos, n. 48. Campinas: IFCH/Unicamp, 2002. Disponível em: http://www.culturaegenero.com.br/download/praticafeminina.pdf. Acesso em: 12 fev. 2020.

PRADO, J. Feminilidades e mídia na cultura contemporânea: culto ao corpo, consumo e sexualidade. 2011. Dissertação (Mestrado em Ciências Sociais) - Faculdade de Ciências e Letras, Universidade Estadual Paulista "Júlio de Mesquita Filho", Araraquara, 2011.

ROSALDO, M. Z. A mulher, a cultura e a sociedade: uma revisão teórica. In: ROSALDO, M. Z.; LAMPHERE, L. (coord.). A mulher, a cultura e a sociedade. Tradução Cila Ankier e Rachel Gorenstein. Rio de Janeiro: Paz e Terra, 1979. p. 33-64.

SANTOS, E. P. A expressão de futuridade verbal em Santo Antônio de Jesus: uma análise variacionista. 2012. Dissertação (Mestrado em Estudo de Linguagens) - Instituto de Letras, Universidade do Estado da Bahia, Salvador, 2012.

SCALZO, M. Jornalismo de revista. 4. ed. 3. reimp. São Paulo: Contexto, 2016.

SARTI, C. A. O feminismo brasileiro desde os anos 1970: revisitando uma trajetória. Revista Estudos Feministas, v. 12, n. 2, p. 35-50, 2004.

SILVA, E. C. A expressão do tempo futuro no português brasileiro dos séculos XVIII ao XX. 2006. Dissertação (Mestrado em Linguística e Língua Portuguesa) - Faculdade de Ciências e Letras, Universidade Estadual Paulista "Júlio de Mesquita Filho", Araraquara, 2006.

TESCH, L. M. A expressão do tempo futuro no uso capixaba: variação e gramaticalização. 2011. Tese (Doutorado em Linguística) - Faculdade de Letras, Universidade Federal do Rio de Janeiro, Rio de Janeiro, 2011.

WEINREICH, U.; LABOV, W.; HERZOG, M. Fundamentos empíricos para uma teoria da mudança linguística. Tradução Marcos Bagno. São Paulo: Parábola Editorial, 2006 [1968]. 